Bayero Journal of Pure and Applied Sciences, 10(2): 277 - 282

Received: November, 2017

Accepted: December, 2017

ISSN $2006-6996$

\title{
ANTIDEPRESSANT ACTIVITY OF METHANOL ROOT BARK EXTRACT OF Securinega virosa (EX WILLD.) BAILL IN ALBINO MICE
}

\author{
${ }^{*}$ Shehu, A ${ }^{1}$, Magaji, M.G. ${ }^{1}$, Sanni, B. ${ }^{1}$ and Abdu-Aguye, S.N. ${ }^{2}$ \\ ${ }^{1}$ Department of Pharmacology and Therapeutics, Ahmadu Bello University, Nigeria \\ 2Department of Clinical Pharmacy and Pharmacy Practice, Ahmadu Bello University, Nigeria \\ *Correspondence author: pharmaishatu@gmail.com, +2348036028298
}

\begin{abstract}
Securinega virosa (S. virosa) is a commonly used medicinal plant in Africa for the management of psychiatric illnesses. Thus, the current study aimed at evaluating the antidepressant activity of the methanol extract of $S$. virosa in mice. The acute toxicity and phytochemical profiles were also determined. The antidepressant activity of the extract $(500,250$ and $125 \mathrm{mg} / \mathrm{kg})$ was assessed using the tail suspension test(TST), forced swim test (FST) and open field test (OFT).The median lethal dose was estimated to be $\leq 2000 \mathrm{mg} / \mathrm{kg}$. Phytoconstituents like tannins, saponins, flavonoids, alkaloids and cardiac glycosides were found to be present in the crude extract. The methanol root bark extract of $S$. virosa significant/y $(p<0.05)$ decreased duration of immobility and also decreased comotion and exploratory behavior in mice. Results obtained from this study showed that the root bark extract of $S$. virosa might possess antidepressant activity.
\end{abstract}

Keywords: Securinega virosa, depression, anxiety, phytochemical

\section{INTRODUCTION}

Securinega virosa ( $S$. virosa) is one of the most useful medicinal plants found in several African countries (Dalziel, 1936). It is used traditionally in the management of psychiatric illnesses in Northern Nigeria (Neuwinger, 1996). The behavioural (Magaji et al., 2008a; Allen, 2011) and analgesic effects (Magaji et al., 2008b) of the methanol root bark extract of $S$. virosa have previously been reported. Depression affects $10-17 \%$ of the global population at some point in life, resulting in enormous personal suffering and economic loss (Ronald, 2014). It is associated with high risk of serious physical health problems (Martin and Hilary, 2012), but still remain a neglected problem in palliative care provision across much African countries (Marina et al., 2012). Depression is different from other types of psychiatric disorders like anxieties, thus it should not be confused as each require different treatment modalities (Muhammad et al., 2013; Gadassi and Mor, 2016). Depression unlike anxiety has suicidal tendencies in addition to the mode alterations. Depression has affected around 300 million individuals across the globe (Calvo-Perxas et al., 2016; Brent, 2016; Filho et al., 2016), and it keep rising outrageously in every community including Nigeria. Factors such as family history, genetic components, life style, environment and diseases were directly or indirectly linked depression (Kimberel et al., 2016, Ridout et al., 2016). However, with all these devastating characteristics of the disease, current therapies are faced with challenges of poor efficacy and side effects, which made neuro-researchers to look inward and discover novel agents with different characteristics (Khan et al., 2018). The present study therefore aimed at evaluating the antidepressant properties of $S$. virosa using forced swim test, tail suspension test and open field test.

\section{MATERIALS AND METHODS}

Reagents and Chemicals

Imipramine (Sigma Aldrich USA), Diazepam (Wuhu Kangi Pharma. Co. Ltd), Normal saline (Dana Pharmaceuticals Ltd), Methanol root bark of Securinega virosa.

Plant Collection and Preparation

Fresh roots of $S$. virosa were collected in Basawa, a town in Sabon Gari Local Government area of Kaduna State, Nigeria in March 2016. The plant was identified and authenticated by a Botanist in the Herbarium section of Biological Sciences Department, Ahmadu Bello University, Zaria by comparing with a voucher specimen number (918) previously deposited. The root was then washed and bark removed. The root bark was dried under shade with intermittent weighing until constant weight was obtained. It was then coarsely powdered with a mortar and pestle. About $100 \mathrm{~g}$ of the coarse powder was extracted with $500 \mathrm{mls}$ of methanol via Soxhlet extraction over 72 hours. The extract was then concentrated and stored in a dessicator until needed for use. Solution of extract was freshly prepared for each experiment.

\section{Phytochemical Analysis}

Phytochemical screening was conducted based on standard protocol (Evans, 1996).

Experimental Animals

Swiss Albino mice of either sex (18-22g) were obtained from the Animal House Facility of Department of Pharmacology and Therapeutics, ABU, Zaria. Mice were kept in propylene cages at room temperature, with standard feed and water ad libitum. Experimental protocols were approved by the university Animal Handling Ethics Committee. Experiment was conducted in a standard neurobehavioral laboratory between $900 \mathrm{~h}$ to $1600 \mathrm{~h}$. 


\section{Acute toxicity studies $\left(\mathrm{LD}_{\mathbf{5 0}}\right)$}

Oral median lethal dose $\left(L D_{50}\right)$ of the extract was estimated in mice according to method previously described by Lorke (1983). Briefly, the method was done in two phases, in the first phase, three groups of three mice each were treated per orally with 10,100 and $1000 \mathrm{mg} / \mathrm{kg}$ body weight and observed for signs and symptoms of toxicity and death for 24 hours. In the second phase, four groups each containing one mouse was treated with four more specific doses of the extract (1200,1600, 2900 and $5000 \mathrm{mg} / \mathrm{kg}$ ). The $\mathrm{LD}_{50}$ was determined by calculating the geometric mean of the lowest dose that caused death and the highest dose for which the animal survived (0/1 and 1/1).

\section{Tail Suspension Test}

Thirty mice were divided into five groups of six mice each. Group 1 was treated with $10 \mathrm{~mL} / \mathrm{kg}$ normal saline, groups 2, 3 and 4 were treated with 500, 250 and $125 \mathrm{mg} / \mathrm{kg}$ of methanol extract of $S$. virosa orally. Group 5 were orally treated with imipramine $10 \mathrm{mg} / \mathrm{kg}$ respectively. One hour later, mice were suspended on the edge of the shelf $58 \mathrm{~cm}$ above a table top by adhesive tape placed approximately $1 \mathrm{~cm}$ from the tip of the tail. The duration immobility was then recorded for a period of 6 minutes (Steru et al., 1985).

Forced Swim Test

Thirty mice were divided into five groups of six mice each. Group 1 was treated with $10 \mathrm{~mL} / \mathrm{kg}$ normal saline, groups 2,3 and 4 were orally treated with 500, 250 and $125 \mathrm{mg} / \mathrm{kg}$ of methanol extract of $S$. virosa respectively. One hour later, each mouse was placed in a plexiglass cylinder tank of $40 \mathrm{~cm}$ height and $18 \mathrm{~cm}$ width filled with $15 \mathrm{~cm}$ water at $25^{\circ} \mathrm{C}$. The total duration immobility was measured over 5 minutes. A mouse was considered immobile whenever it remained floating passively in the water in a slightly hunched but upright position with its nose just above the surface (Alpermann et al., 1992).

\section{Open Field Test}

Thirty mice were divided into five groups with five mice each. Group 1 was treated with $10 \mathrm{~mL} / \mathrm{kg}$ normal saline. Groups 2, 3, and 4 received 500,250, and $125 \mathrm{mg} / \mathrm{kg}$ of methanol extract of $S$. virosa respectively. Group 5 received diazepam (15 mg/kg.) One hour later, each mouse was then placed in white wooden open field apparatus ( $70 \times 70 \times 35 \mathrm{~cm}$, length, breath and height) of which one wall is made of plexiglass. The floor was divided into 16 visible squares $(15 \times 15 \mathrm{~cm})$ with a central square with the aid of marker and covered with a Plexiglas. One hour after treatment, mice were individually placed at the corner of the apparatus and allowed to explore. Behavior of mice was recorded for 5 mins (Rex etal., 1998). Arena was cleaned with $10 \%$ ethanol between tests to remove olfactory cues.

Statistical Analysis

Data obtained were analyzed using one-way ANOVA followed by Dunnett's t- test. A pvalue of $\leq 0.05$ was considered significant.

\section{RESULT}

\section{Phytochemical Analysis}

The phytochemical screening of methanol root bark extract of $S$. virosa revealed the presence of steroids, saponins, alkaloids, tannins, carbohydrates and glycosides (Table 1).

\section{Toxicity studies}

The oral median $\mathrm{LD}_{50}$ was estimated to be greater than $2000 \mathrm{mg} / \mathrm{kg}$ body weight (Table 2 ).

\section{Antidepressant studies}

\section{Tail suspension test}

The methanol root bark extract of S.virosa significantly ( $p \leq 0.05$ ) decreased the duration of immobility at a dose of $125 \mathrm{mg} / \mathrm{kg}$ and500 mg/kg respectively. Similarly, Imipramine significantly $(p \leq$ 0.001 ) decreased the duration of immobility compared to the normal saline treated group (Figure 1).

\section{Forced Swim Test}

The methanol root bark extract of $S$. virosa significantly $(p<0.0001)$ decreased the duration of immobility at all tested doses. Imipramine $(15 \mathrm{mg} / \mathrm{kg})$ also significantly ( $p \leq 0.0001)$ decreases the immobility period as compared to normal saline treated group (Figure 2).

\section{Open Field Test}

The methanol root bark extract of S.virosa significantly $(p \leq 0.001$ and $p \leq 0.05)$ decreased the total number of line crossed at doses of $125 \mathrm{mg} / \mathrm{kg}$ and $500 \mathrm{mg} / \mathrm{kg}$ respectively. Similarly, Diazepam $(10 \mathrm{mg} / \mathrm{kg})$ significantly $(p \leq 0.001)$ decreased the total number of lined crossed(Figure 3). The methanol root bark extract of S. virosa significantly $(p<0.001)$ decrease frequency of stretch to attend posture at doses of $125 \mathrm{mg} / \mathrm{kg}, 250 \mathrm{mg} / \mathrm{kg}$ and $500 \mathrm{mg} / \mathrm{kg}$ when compared with the normal saline treated group. Similarly, diazepam also significantly ( $p \leq$ 0.001 )decreased stretch to attend posture frequency (Figure 4).

\begin{tabular}{ccc} 
Table 1: & Phytochemical constituents of the methanol Root Bark Extract of Securinega virosa \\
\hline S/No & Phytoconstituents & Inference \\
\hline 1 & Alkaloids & + \\
2 & Flavonoids & + \\
3 & Tannins & + \\
4 & Saponin glycoside & + \\
5 & Cardiac glycoside & + \\
6 & Unsaturated Steroids & + \\
& and Triterpenes & + \\
7 & Anthraquinones & + \\
8 & Carbohydrates & + \\
\hline
\end{tabular}

$+=$ present, $-=$ absent 
Table 2: $\mathrm{LD}_{50}$ Values for Methanol Root Bark Extract of Securinega virosa in Mice

\begin{tabular}{llll}
\hline $\mathbf{L D}_{50}$ Value & Onset of toxicity & Duration of toxicity & Signs of toxicity \\
$\geq 2000$ & None & None & None
\end{tabular}

$\mathrm{n}=13$.

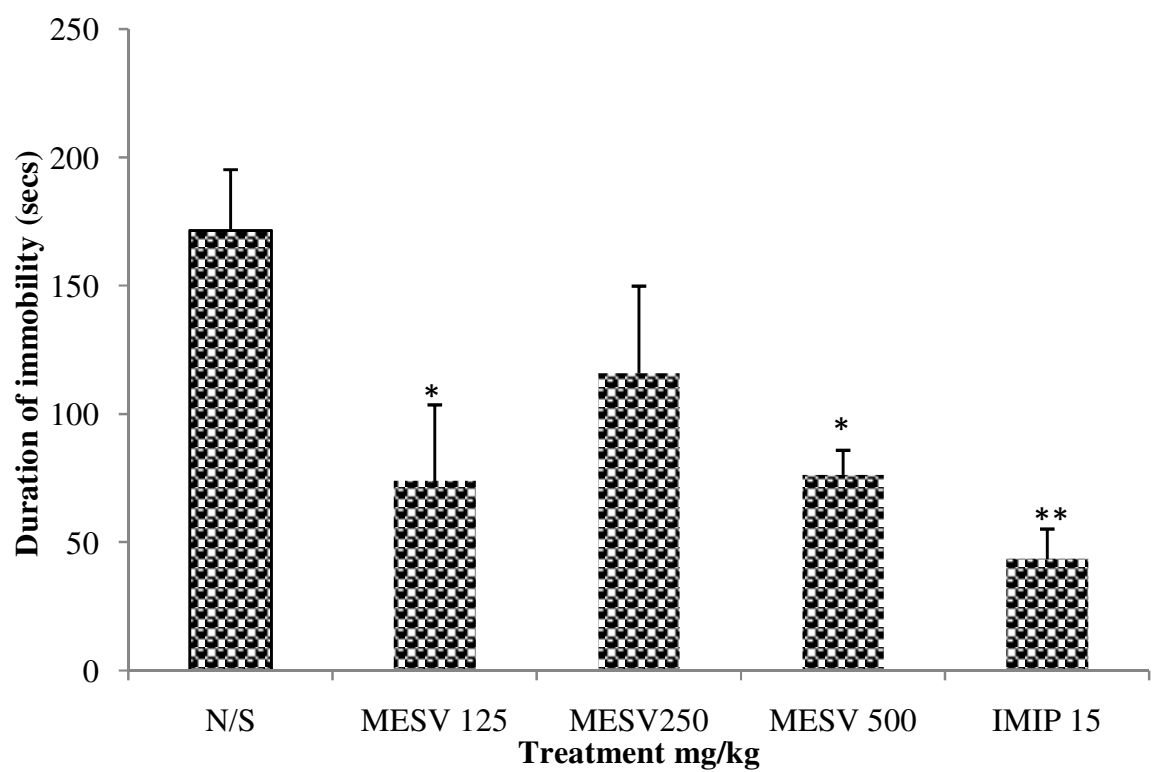

Figure 1: Effect of Methanol Root Bark Extract of $S$. virosa on Duration of Immobility in Mice in the Tail Suspension Test

Data was analyzed using one-way ANOVA followed by Dunnetts t-test and presented as mean $\pm \mathrm{SEM}, *=p \leq 0.05$; $* *=p \leq 0.01$ are significant statistical difference as compared to normal saline treated group, MESV $=$ Methanol root extract of $S$. virosa, IMIP= Imipramine; $n=6$,

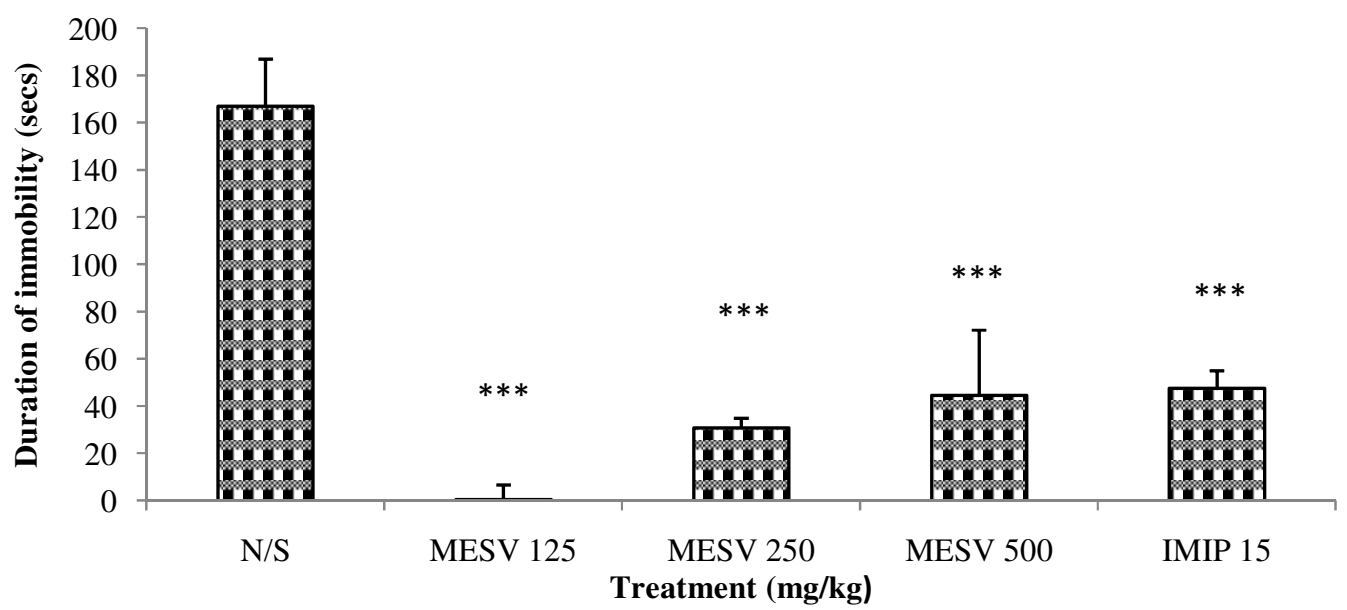

Figure 2: Effect of Methanol Root Bark Extract of $S$. virosa on Duration of Immobility in Mice in the Forced Swim Test

Data was analyzed using one-way ANOVA followed by Bonferoni post hoc and presented as mean $\pm S E M, * * *=$ $\mathrm{P} \leq 0.000$ are significant statistical difference as compared to Control group, MESV= Methanol root extract of $S$. virosa, IMIP = Imipramine, $\mathrm{n}=6$ 


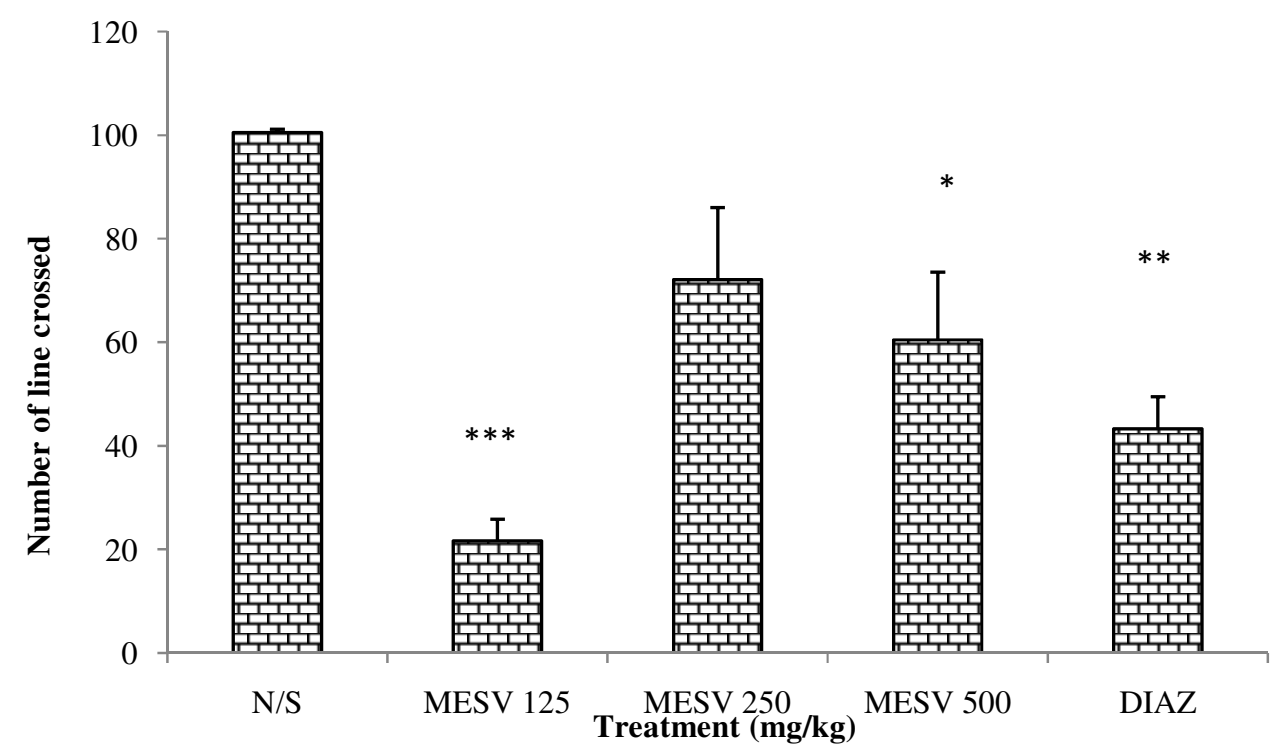

Figure 3: Effect of Methanol Root Bark Extract of $S$. Virosa on the Number of Lines Crossed by Mice in the Open Field Test in Mice

Data was analyzed using one-way ANOVA followed by Dunnett t-test and presented as mean $\pm \mathrm{SEM}, *=p \leq 0.05$, $* *=p \leq 0.01, * * *=p \leq 0.00$ are significant statistical difference as compared to Control group, MESV= Methanol root extract of $S$. virosa, DIAZ= Diazepam, $\mathrm{n}=6$

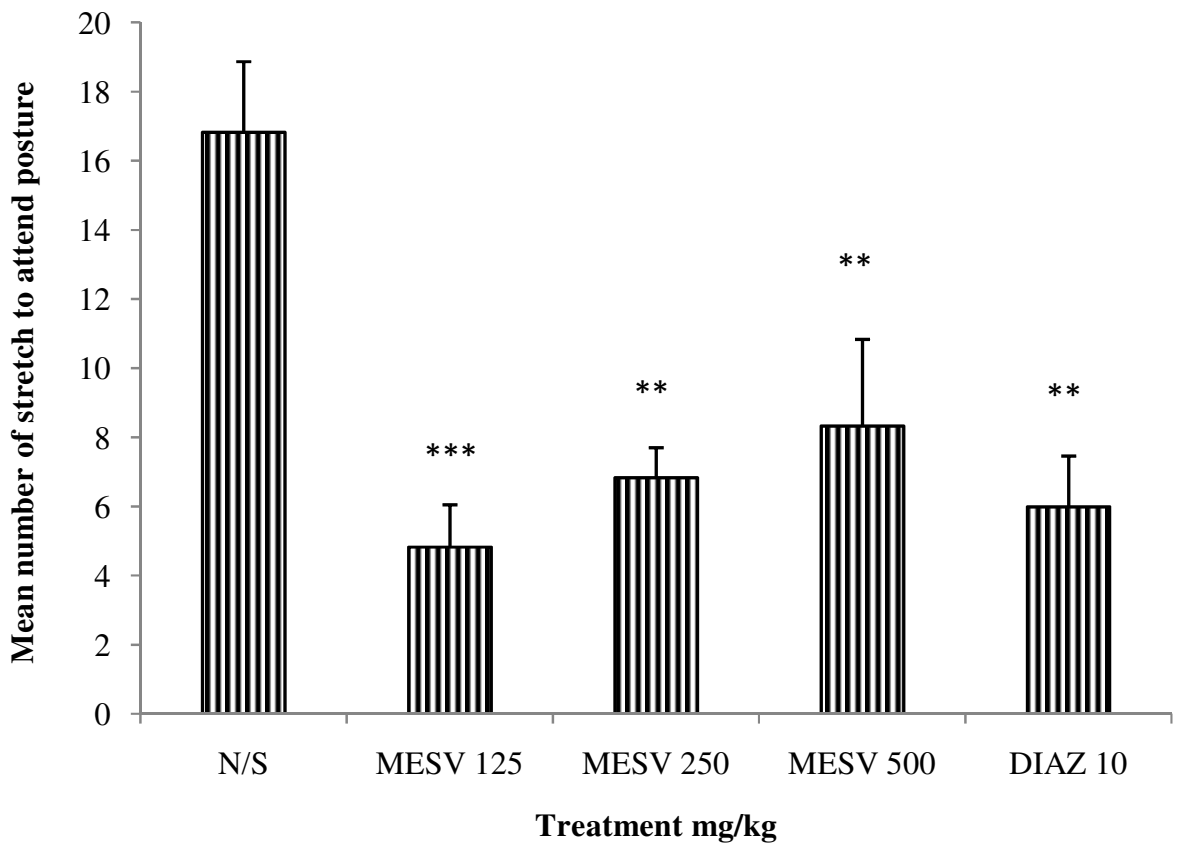

Figure 4: Effect of Methanol Root Bark Extract of S. Virosa on Number of Stretch to Attend Posture by Mice in the Open Field Test

Data was analyzed using one-way ANOVA followed by Dunnett's t-test and presented as mean \pm SEM, $* *=$ $p \leq 0.01, * * *=p \leq 0.001$ are significant statistical difference as compared to normal saline treated group, MESV= Methanol root extract of $S$. virosa, DIAZ= Diazepam, $\mathrm{n}=6$ 


\section{DISCUSSION}

Securinega virosa is reportedly used as stimulant taken as a broth, the leaf sap is used in cases of epilepsy and with other drugs, the plant is used as tranquilizer in sanity in traditional medicine across the world with Nigeria inclusive (Magaji et al., 2008).

The forced swim test is one of the behavioural tests in rodents utilized to predict clinical efficacy of antidepressants and their possible mechanism of action (Borsini and Meli, 1988). Antidepressant such as serotonin reuptake inhibitors (SSRIS) and tricyclic antidepressant (TCA) reverse the immobility posture and enhance escape attempts behavior. Immobility exhibited by rodents when subject to unavoidable stress such as forced swimming and tail suspension reflect a state of despair or lowered mood, which is thought to reflect depressive episodes in humans (Cryan et al., 2005; Everton et al., 2018).Rodents when forced to swim in a cylinder from which they cannot escape will after an initial period of vigorous activity, display a characteristic immobile posture which can be readily identified and is said to reflect a state of despair (Kashani et al., 2018). The methanol root bark extract of $S$. virosa reverses the immobility and promote the occurrence of escape-related behavior in mice.

Due to the draw backs of false positive or false negative associated with forced swim test (Foyet et al., 2014); the tail suspension test was also conducted. In both tests, there was significant reduction of immobility time of mice, and the result was quite comparable to imipramine, the tricyclic antidepressant agent used as standard for the test, indicating that the extract possesses antidepressant activity on the central nervous system.

In order to avoid the false positive response associated with psychostimulants, the effect of extract was tested on locomotion, exploration and anxiety activities in the open field test (Walsh and Cummins, 2001; Yu et al, 2007). The extract did not increase spontaneous motor activity in mice, but rather inhibited the locomotor activity. Suggesting that it

\section{REFERENCES}

Alfred, M. (2013). Traditional use of Medicinal plants in South - Central Zimbabwe. Journal of Ethnobiology and Ethnomedicine, 46: 678 698.

Allen, A. (2001). Coping with Side Effects of Depression, Article on Effective Management of Depression, 13: 24-26.

Allen, A. (2011). Behavioral Effects of the Methanol Root Bark Extract of Securinega virosa in Rodents, 32: $224-226$.

Alpermann, H.G., Schaut, U., Usinger, P. and Hock, F.J. (1992). Pharmacological effects of Hoc 249: A new potential antidepressant, Drug Development Research, 25: 267-282.

Argyii, S. (2015). Clinical Depression, Journal of Clinical Psychiatry, 3: 344 - 346.

Borsini, F. and Meli, A. (1988). Is the forced swimming test a suitable model for revealing antidepressant Psychopharmacology, 94 (2):147-168. possesses general CNS depressant potential as previously reported. Putting all the results together, it can be strongly inferred that the antidepressant activity of methanol root extract of $S$. virosahas no relationship with skeletal muscle stimulation. Furthermore, several well-known antidepressants decrease locomotor activity (Brian and Francois, 2015; Yau et al., 2017). One of the etiologies of depression is alteration in neurotransmitters function, particularly serotonin, noradrenaline and dopamine (Mayor, 2014; Argyii, 2015; Mannan et al., 2015). Therapy with SSRIs has been reported to increase extracellular availability of serotonin (Martin, 2012). Thus, methanol root extract of $S$. virosa may exert its observed antidepressant effect through one or more of the central nervous system neurotransmitters activity on Glutamatergic, GABAergic or Serotonergic pathways. In line with this, researches have previously reported the methanol extract to have antagonized apomorphine induced climbing behavior as well as decreased number of head dips in hole board test in mice (Magaji et al., 2008a). This report supported the central depressant activity observed in this study, proposing the involvement of dopaminergic actions on limbic systems and probably GABAergic systems.

Safety and efficacy are factors of great concern when seeking for a novel drug. The $\mathrm{LD}_{50}$ of the extract was found be around $2000 \mathrm{mg} / \mathrm{kg}$ orally. This is an indications of the plant being slightly toxic as described by Lorke (1983).

The biological or pharmacological actions of plant extracts are known to be due to the presence of specific phytochemical constituents. Antidepressant activities have been linked tosaponins, flavonoids and alkaloids (Haixia et al., 2009; Mohit et al., 2009).Thus the antidepressant effect exhibited by the plant $S$. virosa may be due to the presence of saponins, tannins and alkaloids found present in the plant.

\section{CONCLUSION}

The methanol root bark extract of S.virosa showed potentials for antidepressant activity.

Brent, D.A. (2016). Antidepressants and Suicidality. Psychiatric Clinics of North America 39: 503-512. Brian, H.H. and Francois, N.S. (2015).New Insights on Antidepressant Discontinuation Syndrome. Pharmacology Theory, 59: $67-70$.

Calvó-Perxas, L., Vilalta-Franch, J., Turró-Garriga, O., López-Pousa, S., Garre-Olmo, J. (2016). Gender differences in depression and pain: A two year follow-up study of the Survey of Health, Ageing and Retirement in Europe. Journal of Affective Disorders, 193: 157-164.

Cryan, J.F., Mombereau, C.and Vassout, A. (2005). The tail suspension test as a model for assessing antidepressant activity: review of pharmacological and genetic studies in mice. Neuroscience and Behavioural Reviews; 29 (4-5): 571-625.

Dalziel, J.M. (1936). The useful plants of West Tropical Africa Watmonghs, Idle, London pp 354-355. 
Evans, W.C. (1996). Trease and Evans Pharmacognosy London Villiere Tindal U.K.., Pp 57-77.

Éverton, R.Q.S.,Cristiane, S.F.M.,Enéas, A.F.J., Ademar, S.M.,Bruno, G.P.,José G.S.M. (2018). Linalool-rich essential oils from the Amazon display antidepressant-type effect in rodents. Journal of Ethnopharmacology, 212: 43-49.

Filho, C.B., Jesse, C.R., Donato, F., Del Fabbro, L., de Gomes, M.G., Goes, A.T.R., Souza, L.C., Giacomeli, R., Antunes, M., Luchese, C., Roman, S.S., and Boeira, S.P. (2016). Neurochemical factors associated with the antidepressant-like effect of flavonoid chrysin in chronically stressed mice. European Journal of Pharmacology, 791: 284-296.

Foyet, H.S., Tsala, D.E. and Ngatanko, A.H. (2014). Enhancing spatial memory: Anxiolytic and Antidepressant effects of Tapinanthus dodoneifolius (DC) Danser in Mice. Neurology Research International, 9743808: 1-9.

Gadassi, R. and Mor, N. (2016). Confusing acceptance and mere politeness: Depression and sensitivity to Duchenne smiles. Journal of Behavior Therapy and Experimental Psychiatry, 50: 8-14.

Haixia, D., Ying, C., Xinmin, L., Qiong, W., Liwei, W., William, J. and Yuqing, (2009). W. Antidepressant effects of ginseng total saponins in the forced swimming test and chronic mild stress models of depression. Progress in Neuropsychopharmacology, Biology and Psychiatry, 33:1417-1424.

Kashani, L., Esalatmanesh, S., Eftekhari, F., Salimi, S., Foroughifar, T., Etasam, F., Safiaghdam, H., Moazen-Zaden, E. and Akhondzadeh, S. (2018). Efficacy of Crocus sativus (saffron) in treatment of major depressive disorder associated with post-menopausal hot flashes: a double-blind, randomized, placebo-controlled trial. Archives of Gynecology and Obstetrics,2018: 1-8.

Khan, H., Amin, S. and Patel, S. (2018). Targeting BDNF modulation by plant glycosides as a novel therapeutic strategy in the treatment of depression.

Life Sciences, https://doi.org/10.1016/j.Ifs.2018.01.0 $\underline{13}$

Kimbrel, N.A., Meyer, E.C., DeBeer, B.B., Gulliver, S.B. and Morissette, S.B. (2016). A 12Monthprospective study of the effects of PTSDdepression comorbidity on suicidal behaviour in Iraq/Afghanistan-era veterans. Psychiatry Research, 243: 97-99.

Lorke, D. 1983. A new approach to Acute Toxicity Testing. ArchivesofToxicology, 54: 275-287.

Magaji, M.G., Anuka, J.A., Abdu-Aguye, L., Yaro, A.H. and Hussaini, I.M. (2008). Behavioural Effects of the methanolic Root bark extract of Securinega virosa in rodents. African Journal of Traditional, Complementary and Alternative Medicines, 5(2): 147-153.

Magaji, M.G., Anuka,J.A.,Abdu-Aguye, I, Yaro, A.H. and Hussaini, I.M. (2008). Preliminary studies on the Anti-inflammatory and Analgesic activities of Securinega virosa (Euphorbiaceae) in experimental animal models.Journal of Medicinal Plants Research, 6(3), 17-25.

Mannan, A., Abir, A.B. and Rahman, R. (2015). Antidepressant like effects of methanolic extract of Bacopamonniera in mice. BMC Complementary and Alternative Medicine,15: 337.

Marina, M., Yasamy, M.T., Ommeren, M.V., Dan,C. and Shekhar, S. (2012). Depression a Global Public Health Concern. Medline Medcine, 72: $789-800$.

Martin, G.L. and Hilary, M.L. (2012).Causes of Depression. Ifight Depression. ReviewArticles on Drug Experience, 89: 65 - 73.

Mayor, H. (2014).Etiology of Depression. Mayor Foundation for Medical Education and Research. Journal of Medical Research, 78: 90 - 130.

Mohit, K.B., Mahendra, B. and Shrinivas, K.K. (2009). Antidepressant-like effect of curcumin and its combination with piperine in unpredictable chronic stress-induced behavioural, biochemical and neurochemical changes. Pharmacology, Biochemistry and Behaviour, 92:39-43.

Muhammad, N., Saeed, M., Khan, H., and Haq, I. (2013). Evaluation of $n$-hexane extract of Viola betonicifolia for its neuropharmacological properties. Journal of Natural Medicines, 67: 18.

Neuwinger, J.D. (1996). African ethnobotany-poisons and drugs. Chapman and Hall, Weinheim pp 495-499.

Rex, A., Voigt, J.P., Voits, M. and Fink, H. (1998). Pharmacological evaluation of a modified open field test sensitive to anxiolytic drugs. Pharmacology, Biochemistry and Behaviour, 59: 677-683.

Ridout, K.K., Ridout, S.J., Price, L.H., Sen, S.N and Tyrka, A.R. (2016). Depression and telomerelength: A meta-analysis. Journal of Affective Disorders, 191: 237-247.

Ronald, S.D. (2014). Pathophysiology of depression and innovative treatments: remodeling glutamergic synaptic connections. State of the Art, 16:11-27.

Steru, L., Chermat, R., Thierry, B. and Simon, P. (1985). Tail Suspension test: a new method for screening antidepressants in mice. Psychopharmacology, 85: 367-370.

Walsh, R.N. and Cummins, R.A. (1976). The open field test: a critical review. Psychological Bulletin, 83: 482-504.

Ya'u, J., Malami, S., Abugi, M.A. and Ngura, H.E. (2017). Antidepressant Activity of Ethanol Extract and Residual Aqueous Fraction of Carissa edulis (Apocynaceae) Root Bark in Mice. Tropical Journal of Natural Product Research, 1(3):129-132.

Yu, H.S., Lee, S.Y. and Jang, C.G. (2007). Involvement of $5 \mathrm{HT} 1 \mathrm{~A}$ and GABA receptors in the anxiolytic like effects of Cinnamomum cassia in mice. Pharmacology, Biochemistry and Behaviour, 87(1): 164-170. 